\title{
¿ES POSIBLE EL HEDONISMO? SOBBRE EL SENTIDO DEL PLACER Y SU POSIBILIDAD FÁCTICA A PARTIR DEL GORGIAS DE PLATÓN
}

\author{
Jorge EsPinoza CÁCERES \\ Universidad Diego Portales. Chile
}

Resumen: La presente investigación pretende determinar el sentido del hedonismo a la luz del diálogo platónico el Gorgias, y su posibilidad fáctica. Para ello recurriremos a los distintos análisis referidos al placer a lo largo de este diálogo para destacar la posición del hedonismo sostenida por el Calicles y comprender la crítica platónica al hedonismo radical que identifica el placer con bien.

Palabras clave: Platón, Gorgias, Calicles, placer, bien, hedonismo, distinción.

\section{IT'S POSSIBLE THE HEDONISM? ON THE SENSE OF PLEASURE AND FACTUAL POSSIBILITY FROM PLATO'S GORGIAS}

Abstract: This research aims to determine the meaning of hedonism in the light of the platonic dialogue Gorgias, and his factual possibility. We will draw the different analyzes relating to pleasure along this dialog to highlight the position hedonismheld by Calicles and understand the platonic criticism to radical hedonism that identifies pleasure with well.

Keywords: Plato, Gorgias, Calicles, pleasure, good, hedonism, distinction.

Recibido: 5.03.13 - Aceptado: 2.04.13

Correspondencia: Jorge EsPinoza CÁCEREs. morelli@ug.uchile.cl Tel. (56) 0222452955 Licenciado en Filosofía en Universidad de Chile. (C)Magister en Pensamiento Contemporáneo, Universidad Diego Portales. (C)Magister en Filosofía, Universidad de Chile. 
1

\section{Introducción:}

"Bien conocida" es la doctrina hedonista heredada y desarrollada en la antigua Grecia, especialmente en la segunda mitad del siglo V practicada por un grupo de personas perdido en el tiempo reconocido como los sofistas. "Bien conocida" escribo pues más de alguna vez hemos identificado a alguna persona como hedonista, o calificado tal situación como precisamente hedonista, o incluso nos hemos sentidos seducidos por la idea de reconocernos como hedonistas. Estamos de algún confuso modo familiarizado con esta posición y su curiosa relación con los placeres. Pero de dónde hemos heredado propiamente estas nociones de hedonismo, y qué quiere decir una posición hedonista ¿Hemos conocido propiamente a algún hedonista? ¿O sólo son confusas imágenes, nociones bastardas las que tenemos referidas al hedonismo y su relación con el placer? Nuestro propósito en el presente escrito es tratar de recurrir a una de las tantas fuentes discursivas que conservamos de la antigua Grecia y tratar de discernir -a través de la mirada de Platón- la posición del hedonismo y su relación con el placer. Tratamos de determinar qué sostiene concretamente el hedonismo, y su posibilidad fáctica.

Nuestro $\mu \dot{\varepsilon} \theta 0 \delta o \varsigma$ de trabajo está constituido por dos movimientos, i) la apropiación intuitiva de lo textual; y ii) la selección deliberada de lo textual: i) La primera está referida al ceñimiento textual de los distintos pasajes del Gorgias de Platón referidos al tratamiento del placer y su relación con el hedonismo. Para ello, discutiremos los pasajes seleccionados para tratar de apropiarnos intuitivamente de los distintos análisis de Platón referidos al placer y su vinculación con la posición hedonista. ii) La omisión deliberada de la genealogía o contexto cuando rebasen o no contribuyan al esclarecimiento propiamente tal de los análisis referidos al placer y el hedonismo.

\section{2.- El Gorgias y la posición hedonista ${ }^{1}$.}

El diálogo que vamos a revisar referido al tratamiento de los placeres en Platón es el Gorgias. Pese a que su "tema principal” es el sentido de la retórica, su

${ }^{1}$ Cito de acuerdo a, Diálogos. O. C. Madrid: Biblioteca Básica Gredos. 
contribución referida al tratamiento de los placeres es sugerente y su vinculación con la posición hedonista notable. En este diálogo podemos encontrar -como tal vez en ningún otro diálogo de Platón- una posición radical del hedonismo encarnada por Calicles. La elección de este diálogo en particular responde a que, a nuestro entender, Platón logra en él plasmar de una manera totalmente dramática y coherente la propia posición hedonista a través de un Calicles apasionado, desvergonzado y orgulloso ${ }^{2}$. Consideramos entonces que en este diálogo la posición hedonista está vigorosamente representada. Y no sólo eso, mediante los distintos análisis referidos al placer expuestos por Sócrates, Platón logra develar una observación -o un problema si se prefiere- respecto a la posibilidad fáctica del hedonismo, y la sutil posibilidad de distinguir entre tipos de placeres.

En el análisis de los pasajes referidos al placer omitiremos deliberadamente los dos primeros momentos del diálogo en donde Sócrates conversa primero con Gorgias, y posteriormente con Polo (esto es, desde 447a hasta 481b) ${ }^{3}$. Nos limitamos a analizar el diálogo entre Sócrates y el hedonista radical Calicles, ya que consideramos que en estos pasajes es donde la discusión conforme a los placeres cobra mayor vigor y profundidad y se deja ver por primera vez la posición hedonista con orgullo y vigor.

La incorporación al diálogo por parte de Calicles es inicialmente de sorpresa frente a la postura socrática (481b). El contexto del diálogo es el siguiente: Sócrates viene conversando extendidamente con Polo sobre el objetivo de la retórica. Polo ha afirmado que el objetivo de la retórica es el placer (462c). Tras una serie de vicisitudes -que rebasan la presente investigación- la conversación llega a un punto en donde Polo sostiene que cometer injusticia es mejor que recibirla. Rápidamente su afirmación tropieza con una serie de dificultades al admitir que cometer injusticia es un acto más feo que sufrirlo. (461b-481b) Sócrates toma ventaja de esta reconsideración del acto injusto y le exige a Polo reconocer que lo bello ( $\kappa \alpha \lambda o ́ v)$ es sólo bello en la medida en que participa de la utilidad o de lo placentero o ambas cosas a la vez y, por el contrario, lo feo,

${ }^{2}$ Escribe a este respecto G. M. A. Grube lo siguiente: "La discusión que tiene lugar entre Sócrates y él [Calicles] es una de las más dramáticas que aparecen en Platón. En ella, y personificados en sus dos protagonistas, se alzan frente a frente dos ideales de vida, el de la búsqueda del placer y el da la búsqueda de la verdad, el hedonismo y el amor al conocimiento." G.M.A. Grube, El pensamiento de Platón, trad. Esp. Tomás Clavo Martínez, Gredos: Madrid, 1987, p. 93-94.

${ }_{3}^{3}$ Platón, (1982) Gorgias. Diálogos. O. C. Madrid: Biblioteca Básica Gredos. 
sólo es feo en la medida en que participa de lo inútil ${ }^{4}$, o de lo doloroso, o ambos cosas a la vez. Con esto la afirmación de Polo se hunde, si cometer injusticia es más feo que sufrirla, entonces cometer injusticia sólo puede, o ser más dolorosa, o ser más inútil, y puesto que ambos interlocutores se muestran de acuerdo en que no puede ser más dolorosa, debe entonces ser más inútil, esto es, más malo. Polo es acorralado, su afirmación cometer injusticia es mejor que sufrirla se viene abajo. Sócrates toma ahora la palabra extendidamente en defensa de la justicia, y la necesaria corrección de los injustos

En este momento irrumpe Calicles, quien inicialmente duda si lo dicho por Sócrates entorno al acto injusto y sufrir injusticia es en serio o una broma "típica" de Sócrates. Calicles interroga a Sócrates para determinar si la postura socrática va en serio o no. Sócrates responde que su postura es bastante en serio: cometer injusticia es perjudicial para quien la comete. Calicles más radical y menos tímido que Gorgias y Polo -como el propio Sócrates declara (487a)- retoma el hilo argumentativo de la conversación y agudamente explicita los puntos débiles de sus antecesores y reprocha a Sócrates su aprovechamiento en estos respectos. En definitiva, según Calicles, el error tanto de Gorgias como de Polo es haber confundido -o dejarse confundir por Sócrates- entre la concepción natural ( $\varphi v ́ \sigma \iota \varsigma)$ de la justicia y la concepción convencional (vómos) de la justicia. Aclara Calicles:

"En la mayor parte de los casos son contrarias entre sí la naturaleza y la ley; así pues, si alguien por vergüenza no se atreve a decir lo que piensa, se ve obligado a contradecirse. Sin duda, tú te has percatado de esta sutileza y obras de mala fe en las discusiones; y si alguien está hablando desde el punto de vista de la ley, tú le interrogas desde el punto de vista de la naturaleza, y si habla de la naturaleza, le preguntas sobre la ley. Como acabas de hacer en lo de cometer injusticia y sufrirla. Al hablar Polo de lo que es más feo con arreglo a la ley, tú tomaste el razonamiento con arreglo a la naturaleza" (483a y siguientes).

Hecha esta aclaración Calicles considera estar en condiciones de reafirmar la postura de Polo: naturalmentecometer injusticia es mejor que sufrirla. Polo fue engañado por Sócrates en el momento en que afirmó con vistas a la ley que cometer injusticia es más feo que sufrirla. La contradicción es aparente, el problema estribaba en la confusión entre una consideración natural y una

\footnotetext{
${ }^{4}$ En estos pasajes hay una cierta confusa identidad entre lo bueno y lo útil, al parecer, no muy compatible con los análisis desplegados en el Hipias Mayor. Se entiende en este contexto entonces lo bueno como sinónimo de lo útil, y lo malo como sinónimo de lo inútil.
} 
consideración convencional -por ley- de la justicia. Gracias a esta aclaración Calicles cree poder restituir el objetivo de la retórica en tanto placer y reiterar la identidad entre placer y bien: "En efecto por naturaleza es más feo todo lo que es más desventajoso, por ejemplo sufrir injusticia; pero por ley es más feo cometerla"5. La postura de Calicles es clara, el bien del hombre es el placer, la unidad indivisible e inconfundible entre bien y placer es exacta e inequívoca. Las "artes" -tales como la retórica- cuya finalidad sea procurar placer son ellas mismas totalmente deseables y venerables ya que al procurar el placer procuran el bien. ¿Pero es posible equiparar el bien y el placer?

\subsection{La crisis de la justicia natural.}

El diálogo recobra nuevo vigor con la aparición de Calicles. Sócrates sorprendido se alegra frente a la intervención de este joven hedonista y su desvergonzado orgullo y elocuencia. Considera un gran bien dialogar con Calicles. Y para ello lo invita a definir los términos a investigar: Pregunta Sócrates: “¿No es que el más poderoso arrebate los bienes del menos poderos, que domine el mejor que el inferior y que posea más el más apto que el inepto? ¿Acaso dices que lo justo es otra cosa, o he recordado bien?” (488b) Calicles responde con desdén: "Eso decía antes y ahora lo repito." (Ibid) El diálogo se esclarece, reconocemos los términos sobre los que investigamos: la justicia consiste en que el más fuerte gobierne a placer sobre los bienes de los más débiles y tenga más que ellos. Pero el establecimiento del justo en estos término presenta dos grandes oscuridades, por un lado, qué entiende Calicles por este ambiguo tener más. ¿Más qué? ¿Más comida, más riqueza, más mujeres? Por otro lado, qué entiende Calicles por los más fuertes. Estas dos indeterminaciones van a ser que la consideración de la justicia de Calicles tambalea y tenga que replantear los términos una y otra vez.

Sócrates astutamente pregunta a Calicles si considera que más fuerte, mejor y más poderoso son una y la misma cosa. Calicles responde: "Te digo claramente que son la misma cosa” (488d). Pero qué entiendes por más fuertes Calicles, pregunta Sócrates, ¿entiendes la fuerza como atributos físicos? Calicles

${ }^{5}$ Obsérvese los siguientes fragmentos del extenso discurso proferido por Calicles: "Pero, según mi parecer, los que establecen las leyes son los débiles y la multitud. En efecto, mirando a sí mismo y a su propia utilidad establecen las leyes, disponen las alabanzas y determinan las censuras (...) Por esta razón, con arreglo a la ley se dice que es injusto y vergonzoso tratar de poseer más que la mayoría y a esto llaman cometer injusticia. Pero, según yo creo, la naturaleza misma demuestra que es justo que el fuerte tenga más que el débil y el poderoso más que el que no lo es." (483b y siguientes). 
responde que no se refiere a la fuerza física, de entender así la fuerza una turba de esclavos debería dominarnos conforme a sus atributos físicos, reduciendo la virtud y la justicia a una superioridad numérica o sencillamente física. A partir de una sugerencia de Sócrates Calicles acepta que los más fuertes son los más inteligentes, los de mejor juicio. Transmutación de la justicia en tanto domino del más fuerte, al domino del más inteligente. Pero Sócrates sigue sin entender qué es lo más que tienen que tener los más inteligentes. "Habrá de tener [el mejor], entonces, más parte de estos alimentos que nosotros, porque es mejor, o bien, por tener el mando, es preciso que reparta todo...". Calicles molesto reformula nuevamente la concepción del mejor, ahora en términos del más decidido (491b) Pero sin esclarecer nuevamente a qué se refiere con este enigmático tener más. La concepción del justo por parte de Calicles se vuelve insostenible, cambia una y otra vez a distintos términos. Calicles cambia de estrategia.

\subsection{Primera distinción entre placer y bien a propósito de sus contrarios, dolor y mal.}

Cansado de esta serie de vicisitudes en torno a la justicia, Calicles expone orgullosa y abiertamente la posición que está defendiendo: el hedonismo radical:

“...lo bello y lo justo por naturaleza es lo que yo te voy a decir con sinceridad, a saber: el que quiera vivir rectamente debe dejar que sus deseos se hagan tan grandes como sea posible, y no reprimirlos, sino, que, siendo los mayores que sea posible, debe ser capaz de satisfacerlos con decisión e inteligencia y saciarlos con lo que en cada ocasión sea objeto de deseo" (492a).

Sócrates responde admirado: "Te entregas a la discusión, Calicles, con una noble franqueza. En efecto, manifiestamente ahora estás diciendo lo que los demás piensan, pero no quieren decir." (492d). Por fin tenemos la posición del hedonismo de una forma clara y transparente: debemos no sólo saciar nuestros apetitos, sino estimularlos, acrecentarlos para mayor placer. La vida recta, esto es, la vida buena es la vida del placer. ¿Pero cuáles son los fundamentos de esta postura? ¿Es posible esta pretensión? Sócrates intenta nuevamente aclarar los términos, comprender esta pretensión del hedonismo de la manera que mejor lo sabe hacer, interrogando. Pregunta Sócrates: “AAfirmas que son la misma cosa placer y bien, o hay algún placer que no es bueno?”(495a) Calicles responde: "Para que no me resulte una contradicción si digo que son distintos, afirmo que son la misma cosa". (Ibid) La posición de Calicles es inamovible, placer y bien son lo 
mismo. Pero luego Calicles admite que los que viven felizmente experimentan lo contrario que los desgraciados. Y que los opuestos (tales como la salud y la enfermedad) no pueden presentarse en un hombre al mismo tiempo: Pregunta Sócrates entonces: "También los bienes y la felicidad y sus contrarios, los males y la desgracia, ¿no se toman alternativamente y alternativamente se pierden?” (496c) Evidentemente responde Calicles. "Así pues, si encontramos dos cosas que se pueden perder y tener al mismo tiempo, es evidente que no podrían ser el bien y el mal. ¿Estamos de acuerdo en esto? Examínalo bien y contesta. "(Ibid) Nuevamente Calicles acepta las propuestas de Sócrates, sin percatarse que estas concesiones perjudicaran la identidad entre bien y mal.

Puesto que Calicles acepta que el hambre y la sed son dolorosos y la satisfacción de ambas es placentera (497a), tenemos una curiosa y tal vez necesaria co-presencia del placer y el dolor, relación que no está permitida - según las concesiones previas - entre el bien y el mal. El bien no puedo coexistir al mismo tiempo - menos en el mismo hombre - con el mal. Por lo tanto, la identidad entre bien y placer es desarticulada. Sócrates afirma: "Que no son la misma cosa, amigo, los bienes y los placeres, ni lo son los males y los dolores. Los unos se dejan de experimentar simultáneamente; los otros no, puesto que son distintos. En efecto, ¿cómo podrían ser la misma cosa los placeres y los bienes o los dolores y los males?"6.(497e).

Como Calicles no cede -debido tal vez a su arrogancia o a su incomprensión del asunto- Sócrates armado de paciencia reformula otro contraargumento. Establece que los buenos son buenas en la medida en que participan de lo bueno, y al contrario, los malos son malos en la medida en que participan de lo malo (Ibid). Esta concesión es peligrosa, si la unimos con la posibilidad de que existan personas no-buenas, esto es, cobardes, viles, insensatos, etc. La afirmación de Calicles ya no resiste. Pues, ¿cómo determinamos -distinguimos- entre las personas buenas y malas si ambas participan de los placeres? De acuerdo a la identidad entre bien y placer, los cobardes, los insensatos deberían ser ellos también buenos puesto que participan activamente del placer, esto es, de la bondad. Calicles exaspera, la identidad entre placer y bien está en serias dificultades.

\footnotetext{
${ }^{6}$ Escribe Guthrie: "Calicles mantiene que comer cuando se tiene hambre o beber cuando se tiene ser es placentero si (y sólo sí) se siente hambre y sed. Por lo que el dolor y el placer pueden darse juntos y, en consecuencia, no podrán ser opuestos y deberán ser diferentes de ser feliz y desgraciado, y el placer no será lo mismo que el bien.”W. K. C. Guthrie, Historia de la filosofía griega, Vol. IV Platón, el hombre y sus diálogos: Periodo temprano. tra. Esp. Álvaro Vallejo Campos y Alberto Medina González, Gredos: Madrid, 1990, p. 283.
} 
Jorge EsPinoza Cáceres .: ¿Es posible el hedonismo? Sobre el sentido del placer y su...

\subsection{Segunda distinción entre placer y bien a propósito de los placeres buenos y los placeres malos. \\ “... Cómo si tu creyeras que yo, o cualquier otro hombre, no juzgo que unos

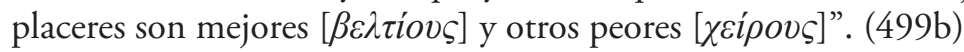

Este cambio abrupto de posición - o reconocimiento - de Calicles es el momento clave, a nuestro entender, de los análisis del placer y su relación con el hedonismo. Calicles después de una larga serie de trabas bien fundadas que Sócrates utiliza contra la identidad entre bien y placer, se ve en la necesidad de reconocer lo que el "sentido común" o la "mayoría” reconoce: la curiosa distinción entre placeres buenos y placeres malos. Sócrates nuevamente sorprendido por Calicles le exige que aclare su nueva postura. Sócrates pregunta: "Al parecer, lo que ahora dices es que unos placeres son buenos [ $\dot{\alpha} \gamma \alpha \theta \alpha i]$ y otros malos [ $\kappa \alpha \kappa \alpha i]$; ¿no es así?" (499c) Calicles afirma. Ahora bien, si existen placeres capaces de ser "juzgados" por malos y otros por buenos. ¿Qué mecanismo opera en el hombre para que esta distinción sea factible? La respuesta es ineludible, se requiere un cierto tipo de conocimiento que desborda el placer mismo. Debemos indagar sobre ese tipo de conocimiento que posibilita la distinción entre tipos de placeres. La alianza entre placer y bien es destrozada. Formalmente hablando, si reconocemos -como el hedonismo pretende- que placer y bien son uno y lo mismo, no podemos con ello reconocer que exista un abanico infinito de placeres entre los cuales podamos encontrar placeres buenos y placeres malos. Nos veríamos obligados -como Calicles se ve obligado- a reconocer que si existen placeres buenos y malos, el placer y el bien no son lo mismo. El bien, por tanto, rebasa al place considerablemente, aunque a veces coincide con él. La evidencia intuitiva en este respecto es ineludible, cotidianamente esta distinción entre tipos de placeres opera en nuestra vida.Cotidianamentereconocemos que existen tipos de placeres distintos, el problema es ahora cómo los distinguimos y si este operación de distinción es identificable sin más con el bien? ${ }^{7}$.

\footnotetext{
${ }^{7}$ Grube escribe: "Sócrates se agarra a esta importante concesión de que unos placeres son buenos y otros malos, interpretándolo desde el primer momento, y con la anuencia de los demás, en el sentido de que unos placeres son útiles y otros son perjudiciales. Los primeros son aquellos que nos proporcionan un bien y que buscamos a causa de ese bien. De igual forma, nos hemos de someter a los dolores beneficiosos. De aquí se deduce otro criterio en orden a la elección de nuestros placeres, de donde resulta que el placer no puede ser ya considerado como nuestro último objetivo. Buscamos el placer en función del bien, y no al contrario." (p. 99).
} 


\section{3.- La posibilidad fáctica de guiarse por los placeres: la posición hedonista.}

Hemos por medio del dialogo platónico del Gorgias comprendido -en la medida posible del contexto- lo que esconde la postura hedonista en su radicalidad, es esto, su pretensión de identificar el bien con el placer y con ello legitimar toda conducta complaciente. Ahora bien, ¿en qué consiste a nuestro entender la crítica platónica del hedonismo? ¿Cuál es el aporte de esta crítica?

Consideramos que la gran contribución de este diálogo platónico es la aclaración detallada de la posibilidad de distinguir entre distintos tipos de placeres, lo que llamaremos aquí como la identificación de los placeres. Nos parece que este es el aspecto fundamental que late a lo largo de los distintos análisis de Platón referidos al placer y lo que alimenta la crítica al hedonismo. Si se prefiere, ésta es la evidencia intuitiva, a saber, la curiosa posibilidad de "distinguir" entre placeres. Aunque el giro platónico de esta evidencia intuitiva en este diálogo en particular consiste en interpretar la curiosa capacidad de "distinguir" entre placeres buenos y placeres malos con vistas a un tipo de conocimiento particular, más precisamente, con vistas al bien, -aunque no sepamos muy claramente en este diálogo qué sea el bien- si reconocemos el sencillo hecho develado por Platón que en la medida que transcurrimos nuestra vida decidimos por ciertos tipos de placeres, y descuidamos otros tipos de placeres, se nos abre la posibilidad de entender la crítica hedonista y su imposibilidad fáctica. Esto es, su imposibilidad de hecho. Ahora se nos muestra claramente que la pretensión hedonista es infundada intuitivamente, bien y placer no pueden ser lo mismo, la vida no puede ser guiada por la sola complacencia de los placeres, ya que esta propia exigencia, esta sospechosa pretensión del hedonismo es fácticamente imposible, nos movemos por la vida constantemente, cotidianamente distinguiendo entre distintos tipos de placeres, -al igual que los presuntos hedonistas y como el propio Calicles- y con ello, el propio placer es siempre rebasado, aliado de algo "otro" en su "determinación” o "elección” de otros placeres ${ }^{8}$. El placer no es el bien. La pretensión hedonista es una ilusión.

Cabe preguntar si la propia posibilidad fáctica del hedonismo, de concretar su pretensión entre identificar bien y placer, es ella misma sólo imposible a partir

${ }^{8}$ Consideramos -al igual que G. M. A. Grube- que el Protágoras "retoma" este problema de la posibilidad del hedonismo y lo lleva a su posición más extrema: el cálculo hedonista.Pero dicho posición tampoco resiste los distintos análisis desplegados por Sócrates, develando nuevamente la necesaria relación o subordinación de los placeres al conocimiento. Confróntese El pensamiento de Platón, trad. Esp. Tomás Clavo Martínez, Gredos: Madrid, 1987, p. 101-108. 
de la caracterización del hedonismo expuesta en estos términos en el Gorgias, o si esta imposibilidad rebasa el análisis del presente diálogoy se extiende a la obra completa de Platón. Tal vez el propio sentido interno del hedonismo, su propia propuesta interna es ella misma imposible fácticamente debido a una incomprensión de la propia vida y los distintos cursos que ella toma en alianza con distintos modos de "conocer" o "creer".

\section{Referencias bibliográficas.}

Burnet, J. Platonis Opera. RecognovitbreviqueadnotationecriticaInstruxit, Oxford: Oxford Classical Texts 1900-1907.

Gómez-Loвo, A. La ética de Sócrates, Barcelona-Buenos Aires-México D.F.Santiago de Chile: Ed. Andrés Bello 1998.

G.M.A. Grube, El pensamiento de Platón, trad. Esp. Tomás Clavo Martínez, Gredos: Madrid, 1987.

W. K. C. Guthrie, Historia de la filosofía griega, Vol. IV Platón, el hombre y sus diálogos: Periodo temprano. tra. Esp. Álvaro Vallejo Campos y Alberto Medina González, Gredos: Madrid, 1990.

Platón, Protágoras, trad. Esp. J. Calonge Ruiz, E. Lledó Íñigo y C. Garcia Gual, Madrid: Gredos 1982.

Platón, Fedón, Traducción, análisis y notas: Alejandro G. Vigo, Buenos Aires, Colihue 2009.

Platón, Gorgias, trad. esp. J. Calonge Ruiz, E. Acosta Méndez, F.J Oliveri y J.L. Calvo: Gredos 1982.

Platón, República, trad. esp. C. EggersLan, Madrid: Gredos 1987. 